\section{Non-destructive analysis of archaeological ochre: a preliminary application to the Middle Stone Age site of Diepkloof Rock Shelter (South Africa)}

\author{
Laure Dayet, ${ }^{1}$ Floréal Daniel,' \\ Pierre Guibert, ${ }^{1}$ Pierre-Jean Texier ${ }^{2}$ \\ 'Institut de Recherche sur les \\ Archéomatériaux, Maison de
}

l'Archéologie, Université de Bordeaux 3, Pessac; ${ }^{2}$ Centre National de la Recherche Scientifique, Unité Mixte de Recherche 5199-De la Préhistoire à l'Actuel:

Culture, Environnement et

Anthropologie, Université de Bordeaux, Talence, France

\section{Abstract}

A number of ochre pieces were found from the Middle Stone Age (MSA) in southern Africa, leading to recent debates about the use of this material. The relevant question behind such a debate lies in the role of ochre in early modern human societies. Technical, socio-economical and symbolic aspects might be associated with ochre processing and use. Ochre pieces showing signs of use-wear found on MSA sites are the main witnesses of such activities. That is why our work has focused on the study of ochre pieces, especially on the issue of the raw material selection. The relevance of non-destructive methods in order to determine the mineralogical nature of ochre is discussed here. Scanning electron microscopyenergy-dispersive X-ray spectroscopy (SEMEDS) and X-ray diffraction (XRD) analyses were used. Based on careful considerations of the association of different features, such as the elementary composition or the fabric, we showed that under certain conditions surface analyses are very useful to assign samples into mineralogical categories.

\section{Introduction}

Ochre is frequently found among archaeological remains on prehistoric sites, as pieces of raw material, modified raw material pieces, powder or residues on artifacts. Several hypotheses were proposed to explain the widespread occurrence of ochre in archaeological deposits, e.g. use as a pigment, in funerary context, for hide-processing, as an adhesive compound for hafting tools, etc. (Wadley et al., 2004; Wreschner et al., 1980; Couraud, 1988).

In southern Africa, hundreds and thousands of pieces were found on several archaeological sites from the Middle Stone Age (MSA) (less than 200 ky old), such as Sibudu Cave, Hollow Rock Shelter, Blombos Cave, Klasies River Mouth or Diepkloof Rock Shelter in South Africa or Apollo 11 in Namibia (Watts, 2009; Wurz, 2000; Henshilwood et al., 2002; Rigaud et al., 2006; Watts, 2002) (Figure 1). For instance, about 9000 pieces were discovered at Blombos Cave (Watts, 2009; Henshilwood et al., 2002) and more than 8000 pieces were reported at Sibudu Cave (Hodgskiss, 2010). A part of the described pieces shows signs of use-wear. The oldest well-described pieces showing use-wear traces were found at Pinnacle Point in South Africa, in layers dated to $160 \mathrm{ky}$ (Marean et al., 2007; Watts, 2010). At Blombos Cave, some pieces showing engravings dated to about 75 ky were discovered (Henshilwood et al., 2002).

Diepkloof Rock Shelter, an MSA site located on the west coast of South Africa, is a recently excavated site with one of the most documented sequence among MSA contexts in southern South Africa (Rigaud et al., 2006; Tribolo et al., 2008; Texier et al., 2010). More than one thousand of ochre pieces were found during the excavations and crayon-shaped pieces were reported. The Diepkloof site offers a unique opportunity to undertake a methodological approach in order to discuss the issue of the raw selection process. Before studying the whole assemblage, a preliminary study on a selection of pieces was conducted in order to test the potential of a non-destructive approach.

\section{Background and research design}

The archaeological term ochre refers to any category of rocks or minerals, containing iron oxides (or oxy-hydroxide), producing a reddish or yellowish streak. The question of the use of this material in southern Africa MSA contexts is debated. On one hand, symbolic meanings are assumed to be linked with ochre use during the MSA (Watts, 2002, 2009, 2010; Henshilwood et al., 2002; Marean et al., 2007; McBrearty and Brooks, 2000). Such an hypothesis is mainly based on ethnographic comparisons, on the color and coloring power of this raw material, and on the possible engravings reported on some pieces. On the other hand, it was argued that ethnographic and some archaeological records are also consistent with utilitarian uses of ochre (Wadley et al., 2004; Lombard, 2007; Soriano et al., 2009). For instance, at Sibudu Cave, ochre residues found on lithic artifacts may refer to a use as an adhesive compound for hafting tools (Lombard, 2007).

Beyond the issue of ochre use in southern
Correspondence: Laure Dayet, Institut de Recherche sur les Archéomatériaux, Université de Bordeaux, Maison de l'Archéologie, Esplanade des Antilles, 33607 Pessac, France.

Tel. +33.557121085 - Fax: +33.650776486.

E-mail: laure.dayet-bouillot@u-bordeaux.fr

Key words: ochre, non-destructive analyses, Middle Stone Age, raw material, mineralogy.

Acknowledgments: we would like to acknowledge the region of Aquitania Region Council and the CNRS for their support to our research project. We also acknowledge the Department of Archaeology of the University of Cape Town, for allowing us to study the ochre pieces from DIEPKLOOF, and Prof. John Parkington for his participation.

Citation: Dayet L, Floréal D, Guibert P, Texier P-J, 2013. Non-destructive analysis of archaeological ochre: a preliminary application to the Middle Stone Age site of Diepkloof Rock Shelter (South Africa). In: RH Tykot (ed.) Proceedings of the $38^{\text {th }}$ International Symposium on Archaeometry - May $10^{\text {th }}-14^{\text {th }} 2010$, Tampa, Florida. Open Journal of Archaeometry 1:e19.

Presented at the $38^{\text {th }}$ International Symposium on Archaeometry - May $10^{\text {th }}-14^{\text {th }} 2010$, Tampa, Florida.

This work is licensed under a Creative Commons Attribution 3.0 License (by-nc 3.0).

(C) Copyright L. Dayet et al., 2013

Licensee PAGEPress, Italy

Open Journal of Archaeometry 2013; 1:e19

doi:10.4081/arc.2013.e19

Africa, the status of the material is a relevant question that needs to be raised. Thus, as there is very little archaeological evidence leading to reliable conclusion about ochre use, we propose to consider the main witnesses of ochre use, namely the raw material and the modified pieces. Indeed, technical, socio-economical and symbolic considerations may have directed the selection of the raw material, which can be discussed through the ochre pieces discovered on a site.

This work first focused on the mineralogical nature of the ochre pieces from Diepkloof. Although pieces of ochre are more and more described among MSA sites, their mineralogical nature were only discussed based on macroscopic examination (Watts, 2002, 2010) The destructive nature of most of the analytical methods used to study ochre pieces (Salomon, 2009; Jercher et al., 1998; Hovers et al., 2003) may have been a limitation to the analysis of this material until now, especially those showing signs of use-wear. Non-destructive methods appear as more suitable in such a context. Electron microscopy coupled with an energy dispersive spectrometer and diffrac- 
tometry were chosen because of their complementarity. In this paper, the usefulness of surface analyses is discussed, as a preliminary research before a wider study on the origin and selection of raw material used to produce ochre at Diepkloof.

\section{Archaeological context and material}

The site of Diepkloof Rock Shelter, Western Cape, South Africa, is located at about $180 \mathrm{~km}$ from Cape Town (Figure 1). The shelter is formed in a quartzitic sandstone rock overlooking a small valley. MSA layers have been excavated since 1998. The main section displays one of the most complete and continuous later MSA sequences in southern Africa, dating from before $130 \mathrm{ka}$ to about $45 \mathrm{ka}$ and encompassing pre-Stillbay, Stillbay, Howiesons Poort, and post-Howiesons Poort occupations (Tribolo et al., 2008). Ochre pieces were selected from the area where the section is the deepest. In that excavated part, more than 550 pieces were collected. Sixty-four samples were selected in order to be analysed. They are distributed throughout the top the sequence (from Post-Howiesons Poort and Howiesons Poort complexes). A potential source of ochre is located directly in the shelter, outcropping within the quartzitic rock. This is a bed of lightly micaceous reddish shale.

\section{Materials and Methods}

\section{Observation}

The first step of the work consisted of the observation of different macroscopic features: mass; texture (fine grained or coarse grained); macroscopic fabric; presence of a cortex; presence of micaceous particles (Table 1). The hardness and the staining power were not considered because they cannot be estimated without scratching the surface of the sample. Indeed, from the beginning to the end of the study, each sample was kept intact. The colour of ochre pieces depends on several factors, such as type of iron oxides, the size and shape of the crystals or the impurities contained in their structure. Therefore, the macroscopic color observation was not considered as a reliable feature for drawing conclusions on the raw material nature. Some depositions were observed on the samples. Water-soluble salts, such as potassium nitrate and sodium chloride, constituted the biggest part of the depositions, according to the surface analysis which was performed before any cleaning. The samples were cleaned using distilled-water before the final analysis.
Scanning electron microscopy coupled with energy dispersive $\mathrm{X}$-ray analysis spectrometer

Whole pieces were analysed with scanning electron microscopy coupled with an energy dispersive X-ray analysis spectrometer (SEMEDS), in order to determine the shape, the size and the elemental composition of every mineral. Analyses were performed on recent fractures whenever this was possible. The SEM instrument is a JEOL $6460 \mathrm{LV}$, the low vacuum system allows the imagery and analysis without specific preparation (coating) of the sample. The SEM is coupled to an EDS spectrometer composed of a SDD semi-conductor (Oxford INCA 30 spectrometer). Due to the porosity and low conductivity of the samples, the qualitative analyses are carried out in low vacuum mode (Pressure: 15-20 Pa; HV: $20 \mathrm{kV}$ ).

\section{X-ray diffraction}

Structural phases were determined by X-ray diffraction. A parallel beam geometry was used to carry out surface analyses (operating with a Göbel mirror and long Soller slits). The data were collected with a Bruker D8 Advance diffractometer, equipped of a PSD Linxeye detector (step by step acquisition mode) and operating with $\mathrm{Cu} \mathrm{K}$ radiation. The $\mathrm{K}$ radiation is eliminated by long Soller slits. Ten very small samples have not been analysed because of the too low signal obtained without an appropriate focalisation system.

\section{Results}

\section{Observation results}

Almost all the samples show a fine-grained texture, and few coarse particles are visible (Figure 2). Sand-size quartz grains are observed on 4 samples only. The sand-size particles represent more than $1 / 3$ of the particle size classes for 2 samples (24 and 28). Some micaceous particles - shiny and platy -shaped, are visible on half of the pieces. A laminar structure - a structure characterised by parallel layers thinner than $1 \mathrm{~cm}$, is also observed among the majority of them (Table 1). Fissility is a common feature among laminar rocks. Such property cannot be tested on all samples but is observed on the most friable ones $(59,76,79)$. The other part of the samples show massive, globular or porous fabric. In most cases, such fabrics are observed collectively on the same samples -massive and globular, massive and porous, etc. A cortex due to weathering condition is observed on at least 9 pieces. Such a cortex is characteristic of pebbles from secondary or sub-primary geological deposition.

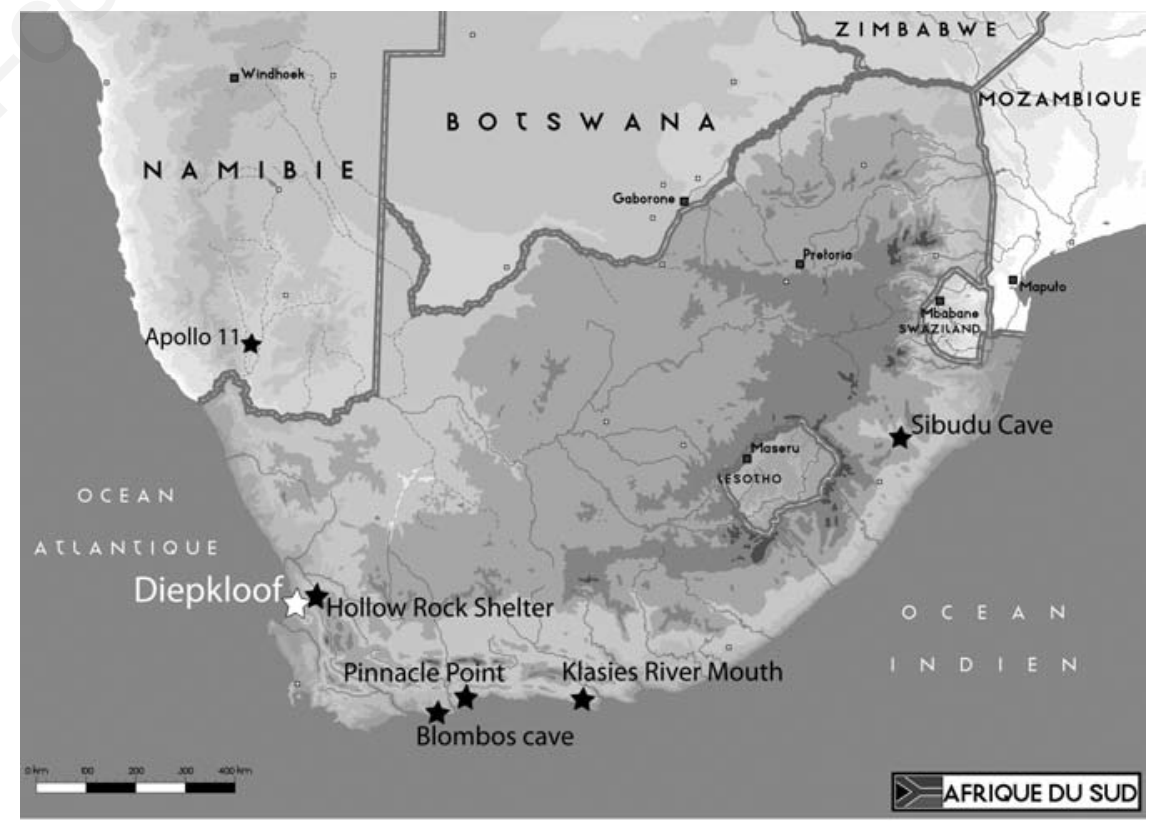

Figure 1. Map showing the main Middle Stone Age southern Africa sites where a number of ochre pieces were found as well as pieces with signs of use-wear. 


\section{Analysis results}

According to the analyses results, samples have been assigned into different categories based on geological or mineralogical characteristics (Table 1). Clay minerals are detected in most of the laminar fine-grained pieces. Thus, they are referred as shale, a fissil mudrock (Blatt and Tracy, 1996). On the other hand, samples containing more than $80 \%$ of $\mathrm{Fe}_{2} \mathrm{O}_{3}$ within the fine fraction after EDS analyses are assigned to a general iron oxide category.

Samples of shale contain illite/muscovite clay mineral. Illite and muscovite are both micalike clay minerals with similar crystallographic structure, and are difficult to distinguish by X-ray diffraction (XRD). Silica, aluminum and potassium, the elements constituting illite/muscovite, are detected by EDS analyses in the fine fraction and in platy silt-size particles (Figure $3 \mathrm{a}$ and $\mathrm{b}$ ). Some pieces of shale also contain kaolinite (detected in 9 samples among 27). In two pieces, a compound constituted by silica, aluminum and magnesium is observed, but no corresponding compound is identified by XRD (68 and 71). Iron oxides are associated to clay minerals. The iron content is variable but remains lower than $50 \%$ in $\mathrm{Fe}_{2} \mathrm{O}_{3}$. They are mostly hematite, detected by XRD in 19 samples, associated with maghemite in one sample (69) and goethite in another one (52). Quartz is present in twelve samples, most of the time as silt-size quartz grains.

Hematite is identified in all the pieces of iron oxide Maghemite/magnetite is identified in several pieces, mixed with hematite (in 14 samples among 27). Maghemite was clearly identified instead of magnetite in one sample only using the (440) ray of maghemite (sample 49). Fined-grain particles that cannot be observed under the magnification permitted by the analysis conditions constitute most of the iron oxide samples. Iron oxide fibrous crystals are distinguished on the surface of twelve samples (Figure 3d). A radial arrangement of the crystals is well-observed. The iron oxide components are mixed with different mineral inclusions, such as quartz grains (detection of $\mathrm{Si}$, present in 14 samples), confirmed by XRD analyses, and possible micas (detection of $\mathrm{Si}$, $\mathrm{Al}$ and $\mathrm{K}$, present in 7 samples). The possible mica particles appear as thin platy-shape particles very similar to those observed in the pieces of shale (Figure 3c). Fine-grained and acicular iron oxides both contain quartz inclusions. Platy particles are more characteristic of fine-grained iron oxides; nevertheless they are detected in some pieces of iron oxide showing fibrous crystals (sample 46).

Aside these two different categories, shale and iron oxide, some samples seem to present intermediate composition features. They were thus discussed separately. They are

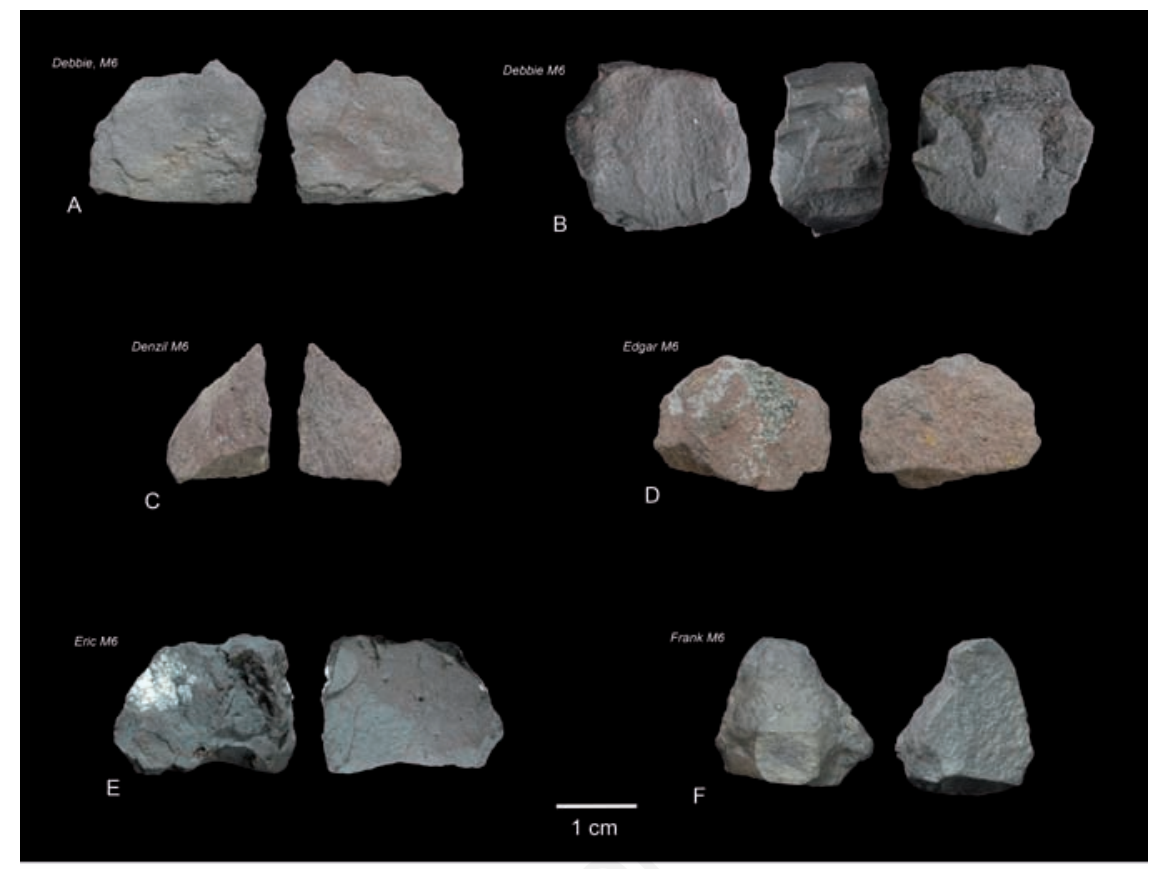

Figure 2. Pictures of some analysed samples: A,D) pieces of shale (17); B,C,F) pieces of fine-grained iron oxide $(22,26,55)$; E) a piece of fibrous crystal iron oxide. Some saltz deposit can be seen on D) and E).

Figure 3. Back-scattered scanning electron microscopy images of the surface of some ochre pieces: a) sample of shale with a clay-rich fine-fraction and platy particles, perpendicular or parallel to the surface $(60)$; b) another sample of shale, with a higher iron content and platy particles (19); c) platy particles on an iron oxide samples (33); d) radial aggregates of fibrous iron oxide with detail of the crystals in the upper right box (38). 
Table 1. Summary of the information about the ochre pieces at stake. The mass and the colour are given to describe samples. The fabric and the $\mathrm{X}$ ray diffraction results are among the main characteristics used to assign samples into rock categories.

\begin{tabular}{|c|c|c|c|c|c|}
\hline $\mathbb{N}^{\circ}$ & Mass (g) & Colour & Fabric & $\mathrm{XRD}$ results & $\begin{array}{l}\text { Type of rocks } \\
\text { (analyses results) }\end{array}$ \\
\hline 15 & 4.1 & Red-purple, dark brown & Laminar & Quartz, illite/muscovite, hematite & Shale \\
\hline 16 & 9.6 & Red-purple, dark red & Laminar & Hematite, maghemite/magnetite, quartz & Shale/iron oxide \\
\hline 17 & 1.8 & Purple & High degree of lamination & Illite/muscovite, hematite & Shale \\
\hline 18 & 1.9 & Purple & High degree of lamination & Illite/muscovite, hematite & Shale \\
\hline 19 & 0.8 & Purple & High degree of lamination & Illite/muscovite, hematite & Shale \\
\hline 20 & 0.5 & Dark red & Massive & - & Silcrete? \\
\hline 21 & 0.5 & Dark red, dark grey & Massive, globular, poreous & Hematite, maghemite/magnetite & Fibrous iron oxide \\
\hline 22 & 8.2 & Dark red & Foliated & Hematite & Iron oxide/shale \\
\hline 23 & 0.6 & Red-purple & Laminar & Illite/muscovite, hematite & Shale \\
\hline 24 & 5.8 & Dark red & Lightly laminar, granular & Hematite, maghemite/magnetite, quartz & Iron oxide (sandstone texture) \\
\hline 25 & 2.6 & Dark red & Lightly laminarr & Hematite & Shale/iron oxide \\
\hline 26 & 1.2 & Purple & Laminar & Hematite, maghemite/magnetite, quartz & Iron oxide \\
\hline 27 & 2.9 & Purple & Laminar & Hematite, quartz & Iron oxide \\
\hline 28 & 2.2 & Dark red, red & Lightly laminar, granular & Hematite, maghemite/magnetite, quartz & Iron oxide (sandstone texture) \\
\hline 29 & 4.5 & Red-purple, dark brown & Laminar & Illite/muscovite, quartz, kaolinite, hematite & Shale \\
\hline 30 & 1.9 & Dark purple & Lightly laminar & 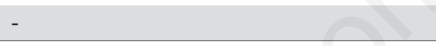 & Iron oxide \\
\hline 31 & 24.1 & Dark red & Massive, poreous & Hematite & Iron oxide \\
\hline 32 & 7.4 & Dark brown & Laminar & Illite/muscovite, quartz, kaolinite, hematite & Shale \\
\hline 33 & 0.2 & Red-purple & High degree of lamination & Hematite, maghemite/magnetite & Shale/iron oxide \\
\hline 34 & 2.2 & Red-pink & Laminar & Quartz, illite/muscovite, hematite & Shale \\
\hline 35 & 0.5 & Red-pink & Laminar & Illite/muscovite, quartz, hematite & Shale \\
\hline 36 & 2.9 & Dark brown & $?$ & Hematite, maghemite/magnetite, quartz & Iron oxide \\
\hline 37 & 1 & Dark brown & Laminar & - & Shale \\
\hline 38 & 4 & Dark red, bright grey & Massive, globular, poreous & Hematite, maghemite/magnetite & Fibrous iron oxide \\
\hline 39 & 3.7 & Dark red, bright grey & Massive, globular, poreous & Hematite, maghemite/magnetite & Fibrous iron oxide \\
\hline 40 & 0.7 & Dark red, grey & Massive, poreous & - & Fibrous iron oxide \\
\hline 41 & 6.4 & Dark red, grey & Massive, poreous & Hematite, maghemite/magnetite, quartz & Fibrous iron oxide \\
\hline 42 & 14.1 & Dark red, grey & Massive, poreous & - & Fibrous iron oxide \\
\hline 43 & 4.1 & Dark red, bright grey & Massive, globular, poreous & Hematite, maghemite/magnetite & Fibrous iron oxide \\
\hline 44 & 1.1 & Dark brown & Massive & Quartz, undetermined & Manganese oxide \\
\hline 45 & 1.9 & Dark red, dark grey & Massive, poreous & - & Fibrous iron oxide \\
\hline 46 & 3.1 & Dark red, dark grey & Massive & Hematite, maghemite/magnetite, quartz & Fibrous iron oxide \\
\hline 47 & 1.2 & Brown, grey & Massive, globular & Hematite, maghemite/magnetite & Fibrous iron oxide \\
\hline 48 & 0.5 & Dark red, grey & Massive, globular, poreous & - & Fibrous iron oxide \\
\hline 49 & 3.9 & Red, dark red & Massive, poreous & Hematite, maghemite & Fibrous iron oxide \\
\hline 50 & 1.2 & Dark brown & Lightly laminar & Hematite, quartz & Iron oxide \\
\hline 51 & 0.3 & Light red-pink & High degree of lamination & Illite/muscovite, quartz & Shale \\
\hline 52 & 2.4 & Red-pink & Lightly laminar & Illite/muscovite, quartz, hematite, goethite & Shale \\
\hline 53 & 1.6 & Red-purple, dark red & Laminar & Hematite, quartz & Shale/iron oxide \\
\hline 55 & 5 & Dark brown & Foliated & Hematite, quartz & Iron oxide \\
\hline 56 & 1.5 & Dark brown & Lightly laminar & Hematite, maghemite/magnetite & Iron oxide \\
\hline 57 & 3.3 & Red, dark brown & Lightly laminar & Illite/muscovite, kaolinite, hematite & Shale \\
\hline 58 & 7.3 & Red, dark brown & Laminar & Illite/muscovite, quartz, kaolinite, hematite & Shale \\
\hline 59 & 5 & Red-pink, red purple & Laminar, fissil & Illite/muscovite, quartz, kaolinite, hematite & Shale \\
\hline 60 & 1.9 & Red-pink & Laminar & - & Shale \\
\hline 61 & 1.4 & Red-pink & Laminar & - & Shale \\
\hline 62 & 2.9 & Red, dark brown & Massive, poreous & Hematite, quartz & Iron oxide \\
\hline 63 & 0.7 & Red & Massive, poreous & - & Iron oxide \\
\hline 64 & 2.7 & Dark brown, black & Massive & Sodium-calcium feldspar & Hornfel? \\
\hline
\end{tabular}


iron-rich pieces, showing iron oxide content $\left(\mathrm{Fe}_{2} \mathrm{O}_{3}\right)$ from 60 to $80 \%$. Alumino-silicates are detected by EDS (presence of $\mathrm{Si}, \mathrm{Al}$ or $\mathrm{Si}, \mathrm{Al}$ and K). Nonetheless no clay minerals are identified by XRD. Amorphous clay minerals may be present. Finally, four samples reveal a composition largely deviating from an ochre raw material. First, they contain less than 5\% of $\mathrm{Fe}_{2} \mathrm{O}_{3}$. Then, three of them are identified as lithic artifact raw materials. One silcrete composed of neoformed silica crystals and two hornfels mainly composed of sodium-calcium feldspars are identified. After EDS analyses, the last sample contains manganese suggesting it is a manganese oxide. Their small size and hue can explain the confusion with ochre materials.

\section{Discussion}

Taphonomic phenomena leading to surface alteration and removal of elements are the main factors that need to be considered when surface analyses are performed. If alterations appear on the whole surface, only destructive methods are suitable to understand their composition and nature. Nevertheless, if alterations are localised, an appraisal of the composition variability and of the surface state might provide proxies to estimate the relevance of surface analyses. 0n Diepkloof ochre pieces, localised depositions were observed on the pieces, localised alterations occurring more frequently than overall alterations on the whole surface. In order to prevent interpretative biases due to localised alterations, the variability of composition need to be discussed. Given that the ranges of variation for the iron, the typical element used for the categorisation, are distinctly different from one category to another, the composition variability within samples in a category seems rather limited. For instance, among iron oxide samples, the range of variation of the fine-fraction appears to be very small considering the number of samples concerned (from about 80 to $95 \%$, but decrease significantly when larger analysis areas are considered (from 5 to $50 \%$ in $\mathrm{Fe}_{2} \mathrm{O}_{3}$ ). Thus, the iron distribution and the iron content are linked with the range of particle size among samples: particles are more sorted among shale samples than among iron oxide 1 samples. Moreover, XRD analyses are in agreement with EDS analyses in the majority of the cases. Illite/muscovite is always detected in samples where iron content is lower than about $50 \%$ (detection limit due to the samples themselves). Such association of factors highlights that alteration phenomena have little influence in the assignment of samples into the shale or iron oxide categories. Moreover, the non-assigned pieces, that can be called iron oxide/shale, represent less than $10 \%$ of the pieces. Such uncertainty in the determination can be attributing to both the diversity of the samples and the limits of nondestructive methods.

In order to discuss the relevance to separate fine-grained from fibrous iron oxide, the links between the type of raw material and different macroscopic features need then to be discussed (Table 2). The laminar structure is a typical feature of all the pieces of shale as expected,

Table 1. Continued from previous page.

$\begin{array}{llllll}N^{\circ} & \text { Mass }(\mathrm{g}) & \text { Colour } & \text { Fabric } & \text { XRD results } & \text { Type of rocks } \\ \text { (analyses results) }\end{array}$

Table 2. Macroscopic features observed among samples depending on the type of raw material determined after the energy-dispersive $\mathrm{X}$-ray spectroscopy and X-ray diffraction analyses.

\begin{tabular}{lcccccccc} 
Raw material analysed & Laminar & Massive & Globular & Porous & Micaceous particles & Cortex & Samples (n) \\
Shale & 27 & 0 & 0 & 0 & 24 & 4 & 0 & 27 \\
Iron oxide/shale & 4 & 0 & 0 & 0 & 5 & 3 & 15 \\
\hline Iron oxide 1 & 8 & 3 & 0 & 3 & 10 & 3 & 1 \\
Iron oxide 2 & 0 & 12 & 6 & 13 & 33 & 13 & 60 \\
\hline Total & 39 & 15 & 6 & &
\end{tabular}

Iron oxide 1 refers to fine-grained iron oxide; iron oxide 2 refers to fibrous iron oxide. 
since such feature clearly defines shale raw materials. Nevertheless, laminar structure is observed on eight among fifteen fine-grained iron oxide samples too (iron oxide 1). The absence of micaceous particles (macroscopic observation) is more specific to iron oxide 1 as only five samples show micaceous particles. The differentiation between iron oxide 1 and shale is even more problematic when samples with intermediate composition are considered. In such case, the composition features only must be used to classify samples. Contrary to iron oxide 1, fibrous iron oxide (iron oxide 2) can be recognised after two macroscopic features. Indeed, radial fibrous crystals on a microscopic scale form a globular fabric at a macroscopic scale. Moreover, such fabric is linked with the presence of pores in ten samples among twelve. Even if not found within the whole surface, the presence of fibrous crystals is relevant enough to be used to assign fibrous iron oxide samples in a separate sub-category among iron oxide. They may form after ironoxide recrystallisations in soils under hard weathering conditions (ferricretes). From a geological point of view, the presence of micaceous particles as a macroscopic feature (also confirmed by EDS analyses), and the laminar fabric within the iron oxide samples may imply similar geological origin contexts. The same hypothesis was proposed regarding iron oxide pieces from Pinnacle Point Cave 13B (Watts, 2010). Finally, the presence of a weathered cortex on iron oxide and on iron oxide/shale pieces is consistent with nodules from secondary or sub-primary outcrops. Although this study is based only 64 pieces, these first results show that almost pure iron oxide of at least two kinds were collected by MSA people along with clayish materials. Shale pieces may come from the source of the shelter, but iron oxide pieces as well as nodules are expected to be exogenous. Their procurement may respond to specific needs, which may be related to their high iron content. Whether such raw materials are available or not near the site remains to be figured out.

\section{Conclusions}

Due to a representative sample of 64 studied pieces and to careful considerations of differ- ent features, we showed that non-destructive analyses, under certain conditions, can provide enough mineralogical information to characterise the raw material of archaeological artifacts. On the contrary, some macroscopic features appeared as not always discriminating between samples which show clear differences in composition. A first classification among the raw materials was thus established. It was possible to discuss the geological origin of some of the identified raw materials. This preliminary work will be used to study the whole assemblage of ochre pieces and to discuss raw material selection. The information obtained will be also helpful to direct future geological field work.

\section{References}

Blatt H, Tracy RJ, 1996. Petrology: igneous, sedimentary, and metamorphic. W.H. Freeman ed., New York.

Couraud C, 1988. [Pigments utilisés en Préhistoire, provenance, préparation, mode d'utilisation]. [Article in French]. Anthropologie 92:17-28.

Henshilwood CS, d'Errico F, Yates R, Jacobs Z, Tribolo C, Duller GAT, 2002. Emergence of modern human behavior: Middle Stone Age engravings from South Africa. Science 295:1278-80.

Hodgskiss T, 2010. Identifying grinding, scoring and rubbing use-wear on experimental ochre pieces. J Archaeol Sci 37:3344-58.

Hovers E, Shimon I, Bar-Yosef 0, Vandermeersch B, 2003. An early case of color symbolism: ochre use by modern humans in Qafzeh Cave. Current Anthropol 44:491522.

Jercher M, Pring A, Jones PG, Raven MD, 1998. Rietveld X-Ray diffraction and $\mathrm{X}$-Ray fluorescence analysis of Australian aboriginal ochres. Archaeometry 40:383-401.

Lombard M, 2007. The gripping nature of ochre: the association of ochre with Howiesons Poort adhesives and Later Stone Age mastics from South Africa. J Hum Evol 53:406-19.

Marean CW, Bar-Matthews M, Bernatchez J, Fisher E, Goldberg P, Herries AIR, 2007. Early human use of marine resources and pigment in South Africa during the Middle
Pleistocene. Nature 449:905-9.

McBrearty S, Brooks AS, 2000. The revolution that wasn't: a new interpretation of the origin of modern human behavior. J Hum Evol 39:453-563.

Rigaud J-P, Texier P-J, Parkington J, Poggenpoel C, 2006. [Le mobilier Stillbay et Howiesons Poort de l'abri Diepkloof: la chronologie du Middle Stone Age sud-africain et ses implications]. [Article in French]. C R Palevol 5:839-49.

Salomon H, 2009. [Les matières colorantes au début du Paléolithique supérieur: sources, transformations et fonctions]. [Thesis in French]. Université de Bordeaux 1, Bordeaux.

Soriano S, Villa P, Wadley L, 2009. Ochre for the toolmaker: shaping the Still Bay points at Sibudu (KwaZulu-Natal, South Africa). J Afr Archaeol 7:41-54.

Texier P-J, Porraz G, Parkington J, Rigaud J-P, Poggenpoel C, Miller C, 2010. A Howiesons Poort tradition of engraving ostrich eggshell containers dated to 60,000 years ago at Diepkloof Rock Shelter, South Africa. P Natl Acad Sci USA 107:6180-5.

Tribolo C, Mercier N, Valladas H, Joron JL, Guibert P, Lefrais Y, 2008. Thermo luminescence dating of a StillbayHowiesons Poort sequence at Diepkloof Rock Shelter (Western Cape, South Africa). J Archaeol Sci 36:730-9.

Wadley L, Williamson BS, Lombard M, 2004. Ochre in hafting in Middle Stone Age southern Africa: a practical role. Antiquity 78:661-75.

Watts I, 2002. Ochre in the Middle Stone Age of Southern Africa: ritualised display or hide preservative? S Afr Archaeol Bull 57:1-14.

Watts I, 2009. Red ochre, body painting, and language: interpreting the blombos ochre. In: R. Botha, C. Knight (eds.) The cradle of language. Oxford University Press, 0xford, pp 62-92.

Watts I, 2010. The pigments from Pinnacle Point Cave 13B, Western Cape, South Africa. J Hum Evol 59:392-411.

Wreschner EE, Bolton R, Butzer KW, Delporte H, Häusler A, Heinrich A, 1980. Red ochre and human evolution: a case for discussion (and comments and reply). Curr Anthropol 21:631-44.

Wurz S, 2000. The Middle Stone Age at Klasies river. University of Stellenbosch ed., South Africa. 